\title{
Focal vs extended ablation in localized prostate cancer with irreversible electroporation; a multi-center randomized controlled trial
}

Matthijs J. V. Scheltema ${ }^{1 *}$, Willemien van den Bos ${ }^{1 \dagger}$, Daniel M. de Bruin ${ }^{1,2}$, Hessel Wijkstra ${ }^{1,3}$, M. Pilar Laguna ${ }^{1}$, Theo M. de Reijke ${ }^{1}$ and Jean JMCH de la Rosette ${ }^{1}$

\begin{abstract}
Background: Current surgical and ablative treatment options for prostate cancer (PCa) may result in a high incidence of (temporary) incontinence, erectile dysfunction and/or bowel damage. These side effects are due to procedure related effects on adjacent structures including blood vessels, bowel, urethra and/or neurovascular bundle. Ablation with irreversible electroporation (IRE) has shown to be effective and safe in destroying PCa cells and also has the potential advantage of sparing surrounding tissue and vital structures, resulting in less impaired functional outcomes and maintaining men's quality of life.
\end{abstract}

Methods/Design: In this randomized controlled trial (RCT) on IRE in localized PCa, 200 patients with organconfined, unilateral (T1 c-T2b) low- to intermediate-risk PCa (Gleason sum score 6 and 7) on transperineal templatemapping biopsies (TTMB) will be included. Patients will be randomized into focal or extended ablation of cancer foci with IRE. Oncological efficacy will be determined by multiparametric Magnetic Resonance Imaging, ContrastEnhanced Ultrasound imaging if available, TTMP and Prostate Specific Antigen (PSA) follow-up. Patients will be evaluated up to 5 years on functional outcomes and quality of life with the use of standardized questionnaires.

Discussion: There is critical need of larger, standardized RCTs evaluating long-term oncological and functional outcomes before introducing IRE and other focal therapy modalities as an accepted and safe therapeutic option for PCa. This RCT will provide important short- and long-term data and elucidates the differences between focal or extended ablation of localized, unilateral low- to intermediate-risk PCa with IRE.

Trial registration: Clinicaltrials.gov database registration number NCT01835977. The Dutch Central Committee on Research Involving Human Subjects registration number NL50791.018.14.

Keywords: Irreversible electroporation, IRE, Prostate cancer, Localized, Focal therapy, Ablation, Randomized controlled trial

\section{Background}

Prostate cancer $(\mathrm{PCa})$ is the most common cancer in men and the second leading cancer-related cause of death. The incidence of $\mathrm{PCa}$ increases steadily, contributors to this increasing incidence include the ageing population, increased awareness and implementation of

\footnotetext{
* Correspondence: m.j.scheltema@amc.nl

${ }^{\dagger}$ Equal contributors

'Department of Urology, AMC University Hospital, Meibergdreef 9, 1105 AZ Amsterdam, The Netherlands

Full list of author information is available at the end of the article
}

the Prostate Specific Antigen (PSA) test [1]. Due to the increasing use of the PSA test and improved diagnostic technology more patients with early stage, localized PCa are diagnosed nowadays.

\section{Present therapeutic options by guideline}

Currently, there are several treatment options available for $\mathrm{PCa}$, including surgery, radiotherapy, minimally invasive ablative techniques and active surveillance. Choice of treatment depends on patients' choice and risk stratification (e.g. D’Amico Risk Classifications [2]). Active surveillance is 
an attractive management option for (very) low-risk PCa. Especially older men, who have the highest incidence of PCa [1], may be suitable candidates for active surveillance (AS) since these patients have a limited life-expectancy and may have co-morbidities. AS can have an impact on quality of life since patients do not receive treatment for their cancer and sometimes the window of opportunity to treat curatively can be missed. For localized disease, a radical prostatectomy or radiotherapy are the recommended curative treatments according to the guidelines [3-5]. The most common side effects associated with radical treatments are: erectile dysfunction (58-79\%), gastrointestinal toxicity and proctopathy (13-34\%), incontinence (range 3.2-14\%), overactive and/or obstructive urinary symptoms and hematuria $(5 \%)[6,7]$. It is the result of procedure-related damage to blood vessels, bowel, urethra and/or neurovascular bundle and may impair the quality of life in PCa patients following treatment [6].

\section{Focal therapy for localized prostate cancer}

The side effect profile of radical treatments opened the door to focal strategies that limit damage to the important anatomical urological structures $[8,9]$. A variety of ablation techniques have been used, including cryoablation, high-intensity focused US (HIFU), radiofrequency ablation (RFA), microwave coagulation, Vascular Targeted Photodynamic Therapy, Interstitial Laser Thermotherapy and Irreversible Electroporation (IRE) [10]. Focal therapy gained popularity because of the minimally invasive approach, short hospital stay, possible improved functional outcomes, lower complication rate and less impact on the quality of life [10]. Moreover, focal treatment provides a more curable treatment option compared to active surveillance and is better tolerated than radical treatments by older patients with comorbidities. A systematic review on focal treatment by Valerio et al. has been published, comprising a total of 2350 cases across 30 studies with a follow-up range between 0 and 11.1 year. In PCa initially treated with focal therapy, the pad-free continence ranged from 95 to $100 \%$, retained erectile function ranged from 54 to $100 \%$ and PCa was absent in 50 to $96 \%$ on regular follow up biopsies [10]. Cheetham and colleagues [11] published promising long-term survival rates of patients undergoing primary or salvage cryotherapy for PCa. Results indicated an $87 \%$ overall 10-year prostate-cancerspecific survival, despite early cryotherapy technology and the majority of patients having high-risk PCa.

\section{Irreversible electroporation for prostate cancer}

Electroporation is a technique in which high-frequent electric pulses are generated between two or more electrodes. The resultant electric current damages the cell membrane, allowing molecules to pass into the cell passively. The process of electroporation can either be temporary (reversible electroporation) or become permanent (IRE) when a certain electric threshold is reached, causing cell death due to the inability to maintain homeostasis [11-13]. Initially, the occurrence of IRE during reversible electroporation procedures was considered an unwanted side effect. However, the ability of IRE to induced selective cell death turned IRE into a tumour ablation modality, leading to the development of the commercially available Nanoknife $^{\mathrm{Tm}}$ (AngioDynamics, Queensbury, New York) [12]. Histopathological outcomes after IRE show a sharp demarcation between ablated and non-ablated tissue, whereas thermal ablation techniques show a transitional zone of partially damaged tissue due to insufficient temperatures for definitive ablation [14]. Therefore, IRE tissue ablation possibly enables more precise procedure planning of the target area. IRE has shown to effectively ablate tumour cells in vitro, in animal studies and in phase 1-2 human trials on IRE (cancer) ablation in several organs (liver, pancreas, kidney, lung and prostate) [15-18]. The first phase 1-2 trials on focal therapy of PCa with IRE have shown promising results, demonstrating a safe and effective focal treatment modality with low patient morbidity, improved functional outcomes and good short-term oncological control [14, 19-22]. No major complications occurred in any of these trials. All of the patients that were continent before the IRE procedure remained pad-free continent, whereas erectile function was preserved in 56 to $95 \%$ of patients that were potent before [21, 22]. In the Phase I-II trial on IRE conducted by the Clinical Research Office of the Endourological Society (CROES) [14], IRE was performed in sixteen patients 30 days prior to their scheduled radical prostatectomy. The histopathological assessment of the prostate showed sharply demarcated necrotic and fibrotic lesions, without skip lesions [14]. This is in concordance with the other phase 1-2 trials with the exception of the study of Valerio et al. where $6 / 34$ patients had possible residual tumour within the ablation zone on multiparametric Magnetic Resonance Imaging (mpMRI) [21]. In the aforementioned study, van den Bos et al. performed Transrectal Ultrasound (TRUS), mpMRI and Contrast-Enhanced Ultrasound (CEUS) imaging following IRE to evaluate the ability of the imaging modalities to accurately visualize IRE ablation effects, ablated area and possible residual PCa. Both mpMRI and CEUS were found to be feasible imaging modalities with concordance in volume to the ablated volume on histopathology with Pearson's correlation of $r=0.88$ and $r=0.80$, respectively [23].

At present, no randomized controlled trial (RCT) (grade $2 \mathrm{~b}$ ) on IRE for treatment-naïve $\mathrm{PCa}$ has been conducted. Moreover, no long-term evidence is available on functional and oncological outcomes following IRE treatment in PCa. In this RCT (NCT01835977) 200 patients with histologically confirmed (on TTMB), organ- 
confined and unilateral low- to intermediate-risk (Gleason score 6 or 7) PCa will receive ultrasound-guided IRE. Selected candidates will be randomized to either 1) focal ablation or 2) extended hemiablation of the tumour lesions to assess the differences in side effect profile and efficacy of the treatment and to investigate if an extended ablation zone is necessary to treat undetected satellite lesions adjacent to the index lesion (Fig. 1) [24]. Patients will be evaluated on urinary continence, erectile function and quality of life with the use of standardized questionnaires [25-27]. Oncological efficacy will be determined by TTMP, preceded by mpMRI and CEUS imaging if available and PSA follow up.

\section{Methods/Design}

Study objectives

Primary

- To evaluate the differences in side effects of patients treated with focal vs extended ablation of PCa with IRE, measured by CTCAE, IIEF, IPSS and use of pads.

- To evaluate the differences in quality of life of patients treated with focal vs extended ablation of PCa with IRE, measured by EPIC, VAS pain score and length of hospital stay.

\section{Secondary}

- To evaluate the oncological efficacy of IRE for focal vs extended ablation of PCa, measured by TTMB 6 months after IRE and 5 year follow-up with mpMRI and serial PSA testing.

- To evaluate the utilization of mpMRI in the oncological follow up after IRE ablation of $\mathrm{PCa}$ and to visualize the extend of the ablation zone, performed 6 months and 1, 2, 3, 4 and 5 years following the IRE procedure.

- If available, to evaluate the utilization of CEUS in the oncological follow up following IRE ablation of $\mathrm{PCa}$ and to visualize the extend of the ablation zone, performed 6 months and 1, 2, 3, 4 and 5 years following the IRE procedure.

\section{Expected outcomes}

It is expected that focal therapy with IRE in localized $\mathrm{PCa}$ has the potential to improve functional outcomes and the quality of life of $\mathrm{PCa}$ patients compared to current radical treatment. In line, it is thought that focal ablation, compared to extended ablation, could better preserve important anatomical structures and consequently have fewer side effects and a higher quality of life score. It is shown that the $2 \mathrm{D}$ target images produced during the preplanning procedure by the Nanoknife ${ }^{\mathrm{Tm}}$ system reflect the IRE ablation zone, and could be used as a template for pathology [14]. Whole mount pathology analysis in prostatectomy specimen, obtained with radical prostatectomy 4 weeks following IRE, showed complete haemorrhage, necrosis and fibrosis in the ablated zone [14, 19]. Therefore, it is expected to find fibrosis on TTMB in the according biopsies of the planned ablated zone. Currently, no long-term oncological outcomes exist on IRE ablation of localized PCa, so it may be difficult to predict longterm outcomes. However, short-term oncological outcomes are promising and the aforementioned study showed on whole mount pathology no residual PCa in the ablated zone of all patients [14, 19-22]. It is thought that mpMRI and CEUS imaging are feasible imaging modalities for the follow-up after focal IRE ablation in localized PCa since both mpMRI and CEUS were found to accurately visualize on a short-term basis IRE ablation effects and possible residual PCa [21-23].

\section{Study design}

In this prospective $\mathrm{RCT}$, patients with unilateral $\mathrm{PCa}$ (clinical stage T1c-T2b), confirmed on transrectal ultrasound(TRUS)-guided biopsies, will be offered extensive (30-core) TTMB. If the inclusion criteria are met (see below and Table 1), candidates are randomized into two groups. One group will undergo a focal ablation of the prostate (Group A), the other group will receive an extended hemi ablation (Group B) (Fig. 1). Prior to the

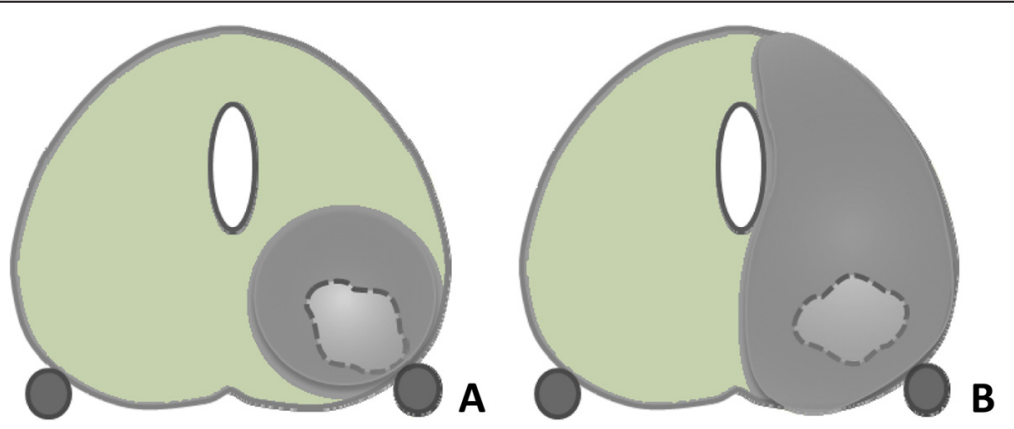

Fig. 1 The Different Ablation Treatments. a Focal Ablation of a PCa lesion in Group A. $\mathbf{b}$ Extended Ablation of a PCa lesion in Group B 
Table 1 Inclusion and exclusion criteria

\begin{tabular}{|c|c|}
\hline Inclusion criteria & Exclusion criteria \\
\hline $\begin{array}{l}\text { 1. Histologically confirmed } \\
\text { organ-confined unilateral PCa } \\
\text { on TTMB (clinical stage T1c-T2b) }\end{array}$ & $\begin{array}{l}\text { 1. Bleeding disorder (prothrombin } \\
\text { time }>14.5 \mathrm{~s} \text {., partial } \\
\text { thromboplastin time }>34 \mathrm{~s} \text {.), } \\
\text { Platelet Count }<140 / \mathrm{uL} \text {, } \\
\text { 2. No ability to stop anticoagulant } \\
\text { or antiplatelet therapy }\end{array}$ \\
\hline 2. Gleason sum score 6 or 7 & $\begin{array}{l}\text { 3. Active (urinary tract) infection } \\
\text { 4. History of bladder neck } \\
\text { contracture } \\
\text { 5. Major concurrent debilitating } \\
\text { illness or ASA } \geq 4 \\
\text { 6. Cardiac History }\end{array}$ \\
\hline $\begin{array}{l}\text { 3. PSA }<15 \mathrm{ng} / \mathrm{mL} \text { or PSA } \\
>15 \mathrm{ng} / \mathrm{mL} \text { counselled } \\
\text { with caution }\end{array}$ & $\begin{array}{l}\text { 7. Inflammatory bowel disease } \\
\text { 8. Major rectal surgery } \\
\text { 9. Previous radiation to pelvis } \\
\text { 10. Prior or concurrent malignancy }\end{array}$ \\
\hline $\begin{array}{l}\text { 4. Life expectancy of }>10 \text { years, } \\
\text { age } \geq 18 \text { years }\end{array}$ & $\begin{array}{l}\text { 11. Biologic or chemotherapy } \\
\text { for PCa } \\
\text { 12. Hormonal therapy within last } \\
6 \text { months } \\
\text { 13. Any resection or stenting of } \\
\text { the prostate } \\
\text { 14. Prostate calcification }>5 \mathrm{~mm}\end{array}$ \\
\hline
\end{tabular}

procedure, a baseline mpMRI, TRUS and CEUS imaging (if available) will be obtained and standardized questionnaires (International Prostate Symptom Score (IPSS), International Index of Erectile Function (IIEF), Quality of life-questionnaire (EPIC), Visual Analogue Scale (VAS)) and number of pads used will be completed by the patients (Fig. 2). After the focal or extended IRE ablation, follow-up will be performed following a strict schedule up to 5 years (Table 2) using mpMRI, TRUS and CEUS imaging (if available), blood tests (PSA, Creatinine), adverse event reporting with Common Terminology Criteria for Adverse Events (CTCAE) and the use of standardized questionnaires (IPSS, IIEF, EPIC, VAS). Six months following the IRE procedure patients will undergo TTMB to determine ablative effectiveness on pathology and to exclude any residual or 'new' disease. In case of any positive biopsies on follow-up TTMB, patients will be offered salvage treatment following the EAU Guidelines on Prostate Cancer [3].

\section{Population}

Two hundred patients (age $\geq 18$ years) diagnosed with histologically confirmed, unilateral organ-confined PCa

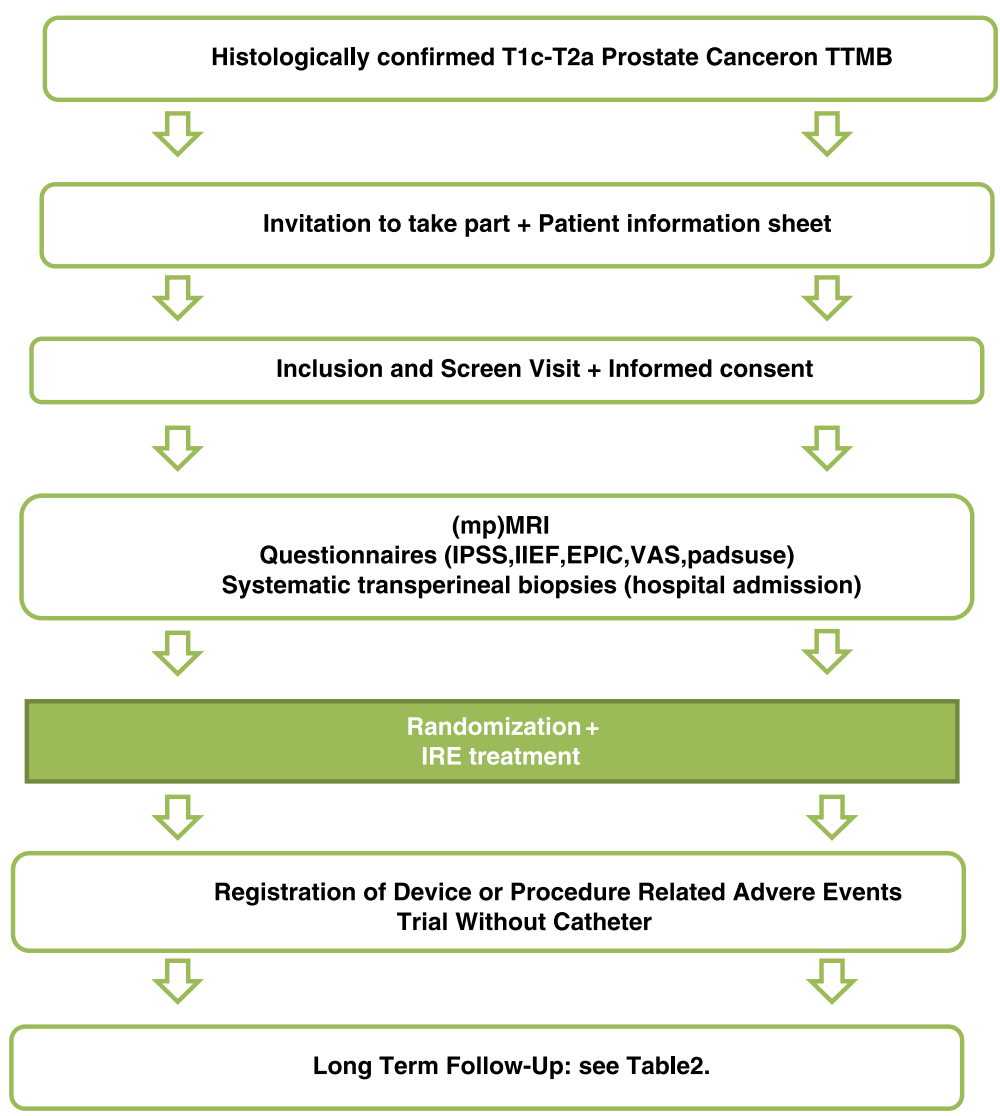

Fig. 2 Flowchart of the inclusion and randomization process 
Table 2 Overview follow-up scheme

\begin{tabular}{|c|c|c|c|c|c|c|c|c|c|c|c|c|}
\hline Visits & Day -1 & Day 0; IRE & Day 1 & 2 weeks & 4 weeks & 3 months & 6 months & 1 year & 18 months & 2 years & 30 months & $3,4,5$ years \\
\hline Medical History & $x$ & & & & & & & & & & & \\
\hline Phys. Examination & $x$ & & & $x$ & $x$ & $x$ & $x$ & $x$ & $x$ & $x$ & $x$ & $x$ \\
\hline Informed Consent & $x$ & & & & & & & & & & & \\
\hline PSA/Creatinine test & $x$ & & & $x$ & $x$ & $x$ & $x$ & $x$ & $x$ & $x$ & $x$ & $x$ \\
\hline $\begin{array}{l}\text { Questionnaires } \\
\text { (IIEF,IPSS,EPIC,pads) }\end{array}$ & $x$ & & & & $x$ & $x$ & $x$ & $x$ & $x$ & $x$ & $x$ & $x$ \\
\hline Pain-scores (VAS) & $x$ & & $x$ & $x$ & $x$ & $x$ & $x$ & $x$ & $x$ & $x$ & $x$ & $x$ \\
\hline $\begin{array}{l}\text { (mp)MRI and if } \\
\text { available CEUS }\end{array}$ & $x$ & & & & & & $x$ & $x$ & & $x$ & & $x$ \\
\hline TTMB & $x$ & & & & & & $x$ & & & & & \\
\hline IRE procedure & & $x$ & & & & & & & & & & \\
\hline AEs reporting & & $x$ & $x$ & $x$ & $x$ & $x$ & $x$ & $x$ & $x$ & $x$ & $x$ & $x$ \\
\hline
\end{tabular}

(clinical score of T1c-T2b) with positive biopsies number on transperineal template-guided prostate biopsies and no evidence of lymph node or distant metastases. Patients should have an expected life expectancy of $>10$ years and serum PSA $<15 \mathrm{ng} / \mathrm{mL}$ or PSA $>15 \mathrm{ng} / \mathrm{mL}$ counselled with caution. Patients known with a cardiac history including arrhythmias, ICD or pacemaker and patients with previous pelvic surgery or radiotherapy or $\mathrm{PCa}$ treatment are excluded. For all inclusion and exclusion criteria, see Table 2 .

\section{Study procedures}

\section{Transperineal template-mapping biopsies}

Extensive transperineal three-dimensional (3D)-template mapping biopsies are performed using ultrasound guidance to localize cancer foci by applying the same transperineal grid used for brachytherapy seed placement. This is considered to be the reference standard for patient selection in focal therapy for localized $\mathrm{PCa}$ [28]. TRUS biopsy, even with optimized protocols, has been shown to poorly reflect the tumour grade and extent of PCa compared with radical prostatectomy specimens [29, 30]. Needle biopsies will be analysed on diagnosis/residual/recurrent $\mathrm{PCa}$ and tumour grade by a specialized uro-pathologist.

\section{IRE ablation}

The AngioDynamics Inc. HVP-01 Electroporation System (also registered as the NanoKnife ${ }^{\mathrm{TM}}$ IRE System) is the first commercially available device based on IRE and is used for tissue ablation that is primarily cellular [13]. It is approved by the regulatory authorities in Europe (CE certificate) and meets several international recognized standards. The NanoKnife ${ }^{\text {тм }}$ System and Probes have been cleared for marketing by the U.S. Food and Drug Administration (FDA) via 510(k) Premarket Notifications (K060054, K080202, K080376, and K080287). The console consists of two major components; a Low Energy Direct Current generator and needle electrodes.

Prior to the procedure patients will receive antibiotic prophylaxis (Ciprofloxacin $500 \mathrm{mg}$ ). A maximum of six IRE electrodes will be placed using a brachytherapy template-grid into the pre-specified ablation zone using biplane transrectal ultrasound image guidance to visualize both sagittal and axial views. The ultrasound data on prostate dimensions, electrode position and electrode tip length are transferred into the software platform and the resultant ablation volume will be determined and displayed by the Nanoknife ${ }^{\text {TM }}$ console (Fig. 3). When the needles are in place, 90 consecutive pulses will be delivered of high-voltage $(1500 \mathrm{~V} / \mathrm{cm})$ with a direct current between 20 and 50 A. Pulses are delivered (synchronized with ECG) in groups of 10 at intervals of $100 \mu \mathrm{s}$. Between each group, a $3.5 \mathrm{~s}$ delay is required to recharge the capacitor. During the IRE procedure patients will receive a strong muscle relaxant (Rocuronium) to prevent severe muscle contraction. The total procedure time, including general anaesthesia, will be approximately $1 \mathrm{~h}$. After the procedure patient will receive a transurethral catheter for $24 \mathrm{~h}$. Patients will have an overnight hospital stay and it is anticipated that the majority of patients will be discharged the day after the procedure. Procedural and post procedure Adverse Events (AEs) and Serious AEs will be reported to the Institutional Review Board (IRB).

\section{Multiparametric magnetic resonance imaging}

mpMRI will be performed in supine position on a $1.5 \mathrm{~T}$ AVANTO $^{\circ}$ MRI scanner (Siemens Healthcare, Erlangen, Germany) using an integrated endorectal-pelvic phasedarray coil (Medrad, Warrendale, USA). Prior to the mpMRI, anti-Peristaltic Drugs (Buscopan or Glucagon) will be given. T2 weighted sequences will be performed in sagittal, coronal and transverse planes from the aorta bifurcation to the pubic symphysis, including prostate 

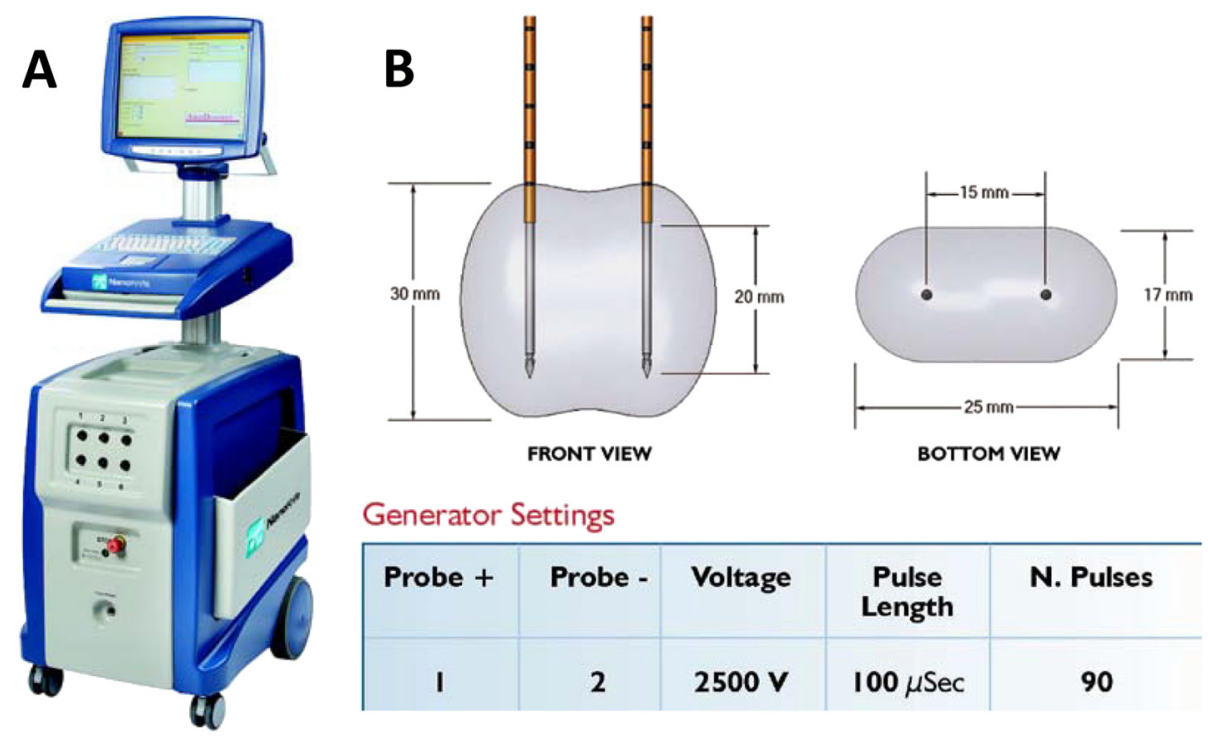

BOTTOM VIEW

Generator Settings

\begin{tabular}{|c|c|c|c|c}
\hline Probe + & Probe - & Voltage & $\begin{array}{c}\text { Pulse } \\
\text { Length }\end{array}$ & N. Pulses \\
\hline I & 2 & $2500 \mathrm{~V}$ & $100 \mu \mathrm{Sec}$ & 90 \\
\hline
\end{tabular}

Fig. 3 a The Nanoknife console. b Specific ablation zone: with the needles placed $1.5 \mathrm{~cm}$ apart, the active electrode length is set at $2 \mathrm{~cm}$ and the resultant ablation volume is calculated at $12.75 \mathrm{~cm}^{3}$

and seminal vesicles. Next, T1 diffusion-weighted with fat suppression and dynamic contrast-enhanced images (0.1 mmol of gadopentetate dimeglumine per kg of body weight, Gadolinium DTPA, Gadovist) are obtained. mpMRI will be evaluated by a specialized uro-radiologist (blinded for the randomization) on prostate and ablation volume, evidence of residual or recurrent $\mathrm{PCa}$ according to the PIRADS (v2) criteria [31], skip lesions within the target zone, damage to adjacent structures and lymph node or haematogenous metastasis.

\section{Contrast-enhanced ultrasound}

CEUS imaging involves the use of microbubble contrast agent (SonoVue; Bracco, Milan, Italy) to show blood flow and tissue perfusion information. The ultrasound contrast agent consists of a solution of gas-filled shellstabilized microbubbles with a diameter of 3-5 $\mu \mathrm{m}$. These bubbles stay inside the blood stream and travel through all blood vessels, including the microvasculature [32] and are visualized with specialised imaging techniques (Philips iU22; Philips Healthcare, Bothell, USA). The prostate will be scanned in 4 planes, base, midbase, mid-apex and apex. If performed, CEUS imaging will be analysed on prostate and ablation volume and evidence of residual or recurrent PCa by the performing urologist/fellow.

\section{Randomization, sample size and statistical analysis Randomization}

The patients are stratified on baseline total IIEF-score with cut-off score of 45 points ( $\leq 45$ vs. $>45$ ), Gleason score (grouped in Gleason sum score 6 vs. sum score 7) and age with cut-off score of 60 years $(\leq 60$ and $>60)$ to prevent randomly occurring differences in important prognostic factors across the two randomized groups. Patients are blinded to the randomized treatment given (focal or extended ablation) to ensure unbiased assessment. The treating physicians have to be informed about the actual treatment in order to be able to perform the ablation. mpMRI findings will be coded and centrally assessed by a uro-radiologist, blinded for the results of TTMB and the performed procedure.

\section{Sample size calculation}

Since the primary objective of the study is to determine the side effect profile of IRE, the sample size is powered on a common event; erectile dysfunction. Ahmed et al. performed three comparable studies with a concurrent focal ablation modality (HIFU), and a similar patient population and the same primary objectives [33-35]. Focal ablation with HIFU led to a decline of $18.2 \%$ on the IIEF-15 questionnaire $(57.5 \%$ to $47.0 \%$ after 12 months). Converting this to the shortened IIEF-5 questionnaire (which is used in this RCT), the mean IIEF score is 16.61 (SD 4.0) in Group A (focal ablation) and the mean IIEF score is 15.1 (SD 4.0) in Group B (extended ablation). A two group Wells-Satterthwaite $t$-test of equal means and unequal variances were used to calculate the sample size. The one-sided (one-tailed) test was used, because this rejects the null hypothesis for differences in a single direction. With an $\alpha$ level of 0.05 and power of $80 \%(1-\beta)$, the sample size required was at least 90 men per group. The sample size was adjusted to allow for $35 \%$ of men in the general population ( $>50$ years old) having 
poor baseline erectile function [36], and therefore aim to recruit at least 200 men in total.

\section{Statistical analysis}

Data will be collected using the Data Management System of CROES. The validated questionnaires will be analysed with standard methods. Maximum and minimum values will be set according to the extremes of questionnaire item scales. Categorical outcomes will be reported as point estimates with binomial $95 \%$ CIs to demonstrate level of precision. Wilcoxon signed rank test (two-tailed) will be used to assess differences between continuous variables that were not normally distributed (PSA and questionnaire scores), measured at baseline and at the subsequent follow-up visit. Changes over time will be reported with box-and-whisker plots. The group analyses will be hypothesis-generating and we will run statistical tests of significance.

\section{Quality and patient safety monitoring}

Data will be centrally collected and monitored by the CROES using their Data Management System. During the study independent physicians and the IRB, assessing patient safety and treatment efficacy, will monitor data. Monitoring criteria are objectively described in the protocol approved by the IRB, since IRE ablation of soft tissue is a novel prostate cancer treatment and therefore holds potential risks and side effects that are unknown at this time. A clinical risk analysis associated with the NanoKnife ${ }^{\text {Tx }}$ device and the procedure is presented in Table 3. In accordance to section 10, subsection 1, of the Wet Medisch-Wetenschappelijk Onderzoek met Mensen (Medical Research Involving Human Subjects Act), the investigator will inform the subjects and the reviewing

Table 3 A clinical risk analysis associated with the IRE device and procedure

\begin{tabular}{ll}
\hline $\begin{array}{l}\text { Potential risks of IRE } \\
\text { ablation and procedure }\end{array}$ & Side effect/Adverse event \\
\hline General Anaesthesia & $\begin{array}{l}\text { Aspiration, urinary retention, extended } \\
\text { muscle blockage, anaesthetic drug toxicity, } \\
\text { pain, coma, death } \\
\text { Cardiac arrhythmias, severe muscle } \\
\text { contraction, electrical shock, death }\end{array}$ \\
Multiple Prostate Biopsies & $\begin{array}{l}\text { Bleeding, infection, pain, urinary retention, } \\
\text { pain }\end{array}$ \\
$\begin{array}{l}\text { IRE needle placement } \\
\text { and ablation }\end{array}$ & $\begin{array}{l}\text { Damage to urethra/bowel/bladder/nerve } \\
\text { with consequent side effects }{ }^{\mathrm{a}} \text {, bleeding, } \\
\text { infection, pain }\end{array}$ \\
Insufficient IRE treatment & $\begin{array}{l}\text { Residual or recurrent tumour } \\
\text { Insufficient Muscle }\end{array}$ \\
Blockade & $\begin{array}{l}\text { Muscle strains or damage, electrodes } \\
\text { displaced, trauma }\end{array}$ \\
\hline
\end{tabular}

ahaematuria, hematoma, infection, abscess formation, fistula, sepsis, death, urinary retention, urinary or faecal incontinence, urethra stricture, erectile dysfunction, necrosis of affected tissue accredited IRB if anything occurs of which the disadvantages of participation may be significantly greater than was foreseen in the research proposal. The study will be suspended pending further review by the accredited IRB, except insofar as suspension would jeopardise the subjects' health. The local investigator will inform all participating subjects. Interdepartmental monitoring (IDM) will take place according to the IDM model in the AMC.

\section{Ethical consideration}

This RCT will be conducted in accordance to the standards of Good Clinical Practice, with the ethical principles that have their origins in the Declaration of Helsinki (Fortealeza, Brazil, October 2013) and is approved by the IRB of the Academic Medical Center, Amsterdam (2014_303). The protocol is registered with The Dutch Central Committee on Research Involving Human Subjects (NL50791.018.14) and on the clinicaltrials.gov database (NCT01835977). Potential patients will be informed about the study by one of the principal investigators or its representatives, provided with the patients information form. When patients agree to participate, written informed consent is acquired from all participants.

\section{Availability of data and materials}

The study initiator, international coordinating researcher and biostatistician will have access to all data in the CROES system, participating centres will only be able to access and register their own data. All data is available for audit and all data will be published in an international peer-reviewed medical journal. After the finalization of the study, the dataset supporting the conclusions of this study will not be shared since permission was not obtained from all participating centres.

\section{Discussion}

The first phase I-II trials on focal therapy of PCa with IRE have shown promising results for IRE as a safe and effective focal treatment modality with low patient morbidity, improved functional outcome and good short-term oncological control [14, 21, 22]. However, there is a need of larger, uniform randomized controlled trials evaluating long-term oncological outcomes to make IRE an accepted and safe therapeutic option in PCa. This study will be the first RCT (Grade 2b) with IRE for treatment-naïve, unilateral low- to intermediate risk $\mathrm{PCa}$, evaluating patients' functional outcome, quality of life and oncological control following focal (group A) or extended (group B) ablation. Two hundred patients will be included and followed up to 5 years with the use of standardized questionnaires, mpMRI, CEUS imaging if available, TTMB and serial PSA testing.

In this trial TTMB is used to select patient for focal therapy in localized $\mathrm{PCa}$, as recommended after an 
international consensus meeting [28]. However, special computer models of 3D whole mount prostatectomy specimens were compared in a small series $(n=25)$ to their corresponding TTMB cores. Eighteen out of sixty four lesions were missed (only 1 was clinically significant) by TTMB and sum Gleason score was upgraded in $12 \%$ $(n=3)$ [30]. A concurrent study by $\mathrm{Hu}$ et al. showed the superiority of TTMB above TRUS-guided biopsies in diagnosing and staging PCa but TTMB regimen still missed $5 \%$ of $\geq 0.2 \mathrm{~mL}$ and $\geq 0.5 \mathrm{~mL}$ lesions [29]. This highlights the confounding factor that TTMB has on accurate patient selection, treatment zone determination and oncological follow-up. In line, PCa foci may also be missed on mpMRI. mpMRI data (on a $1.5 \mathrm{~T}$ device) compared to whole mount prostatectomy specimen showed sensitivity/specificity and positive/negative predictive values for detection of PCa by mpMRI of $77 / 91$ and $86 \% / 85 \%$ for foci of $>0.2 \mathrm{~mL}$ and $90 / 88$ and $77 \% /$ $95 \%$ for foci of $>0.5 \mathrm{~mL}$, respectively [37, 38]. However, in a recent study $(n=50)$ the combination of mpMRI with TTMB, used in a RCT, was found to have a high negative predictive value (91 \%) for low-grade, small volume (>3 mm) PCa, indicating a reliable assessment to prevent undertreating significant PCa [39]. Since pathological assessment following IRE showed fibrosis without glandular prostatic ducts and necrotic tissue and no skip lesions within the ablated zone, we believe IRE effectively ablates all PCa foci within the target zone. Tumour ablation experiments in animals and humans have shown the potential to preserve connective tissue structures within the target zone and limit damage to associated blood vessels, neural tissue or other vital structures [16-18]. However, this may not apply to current thorough clinical treatment protocols $[14,40]$.

Therefore, in our opinion this RCT will provide important data on the differences between focal or extended ablation of localized, unilateral low- to intermediate-risk PCa using IRE, providing essential long-term data on functional outcome and oncological control.

\footnotetext{
Abbreviations

(mp)MRl: (multiparametric) Magnetic Resonance Imaging; A: ampere; AE: adverse event; AS: active surveillance; CEUS: Contrast-Enhanced Ultrasound; CROES: Clinical Research Office of the Endourological Society; CTCAE: Common Terminology Criteria for Adverse Events; EPIC: Quality of life-questionnaire; HIFU: high-intensity focused ultrasound; IDM: interdepartmental monitoring; IIEF: International Index of Erectile Function; IPSS: International Prostate Symptom Score; IRB: Institutional Review Board; IRE: Irreversible Electroporation; PCa: Prostate Cancer; PSA: Prostate Specific Antigen; RCT: randomized controlled trial; RFA: radiofrequency ablation; SAE: serious adverse event; SD: standard deviation; TRUS: Transrectal Ultrasound; TTMB: transperineal templatemapping biopsies; V: Volt; VAS: Visual Analogue Scale.
}

\section{Competing interests}

$J d l R$ is paid consultant to AngioDynamics. All other authors of this manuscript declare no relationships with any companies, products or services related to the matter of this study.

\section{Authors' contribution}

$M J S, W B, D M d B$ and JdIR conceived the trial concept and designed the protocol. WH, MPLP, and ThMdR helped develop the trial design and protocol. JdIR is the principle investigator and end responsible for trial design, the protocol and trial conduct. All authors aided in drafting the manuscript. All authors have read and approved the final manuscript.

\section{Acknowledgements}

The charity foundation Cure for Cancer Foundation awarded a scientific grant for the design and conduct of this study. Wijnstok NJ for reading the manuscript and statistical support.

\section{Author details}

'Department of Urology, AMC University Hospital, Meibergdreef 9, 1105 AZ Amsterdam, The Netherlands. ${ }^{2}$ Department of Biomedical Engineering and Physics, AMC University Hospital, Amsterdam, The Netherlands. ${ }^{3}$ Signal Processing Systems, Eindhoven University of Technology, Eindhoven, The Netherlands.

Received: 23 February 2016 Accepted: 1 May 2016

Published online: 05 May 2016

\section{References}

1. Siegel R, Naishadham D, Jemal A. Cancer statistics, 2012. CA Cancer J Clin. 2012;62:10-29.

2. D'Amico AV. Cancer-specific mortality after surgery or radiation for patients with clinically localized prostate cancer managed during the prostate-specific antigen Era. J Clin Oncol. 2003;21:2163-72.

3. Mottet N, Bellmunt JEB, Bergh R, Bolla M, Casteren N, Conford P. EAU Guidelines on Prostate Cancer. 2015. February.

4. Parker C, Gillessen S, Heidenreich A, Horwich A. Cancer of the prostate: ESMO clinical practice guidelines for diagnosis, treatment and follow-up. Ann Oncol. 2015;24(February 2002):mdv222.

5. Thompson I, Thrasher J, Gunnar Aus M, Burnett A, Canby-Hagino E, Cookson M, D'Amico A, Dmochowski R, Eton D, Forman J, Goldenberg S, Hernandez J, Higano C, Kraus S, Moul J, Tangen C. Guideline for the management of clinically localized prostate cancer: 2007 update. 2009.

6. Sanda MG, Dunn RL, Michalaski J, et al. Quality of life and satisfaction with outcome among prostate cancer survivors. N Engl J Med. 2008;358:1250-61.

7. Resnick MJ, Koyama T, Fan K-H, Albertsen PC, Goodman M, Hamilton AS, Hoffman RM, Potosky AL, Stanford JL, Stroup AM, Van Horn RL, Penson DF. Long-term functional outcomes after treatment for localized prostate cancer. N Engl J Med. 2013;368:436-45.

8. Marberger M, Carroll PR, Zelefsky MJ, Coleman JA, Hricak H, Scardino PT, Abenhaim LL. New treatments for localized prostate cancer. Urology. 2008;72(6 Suppl):S36-43.

9. Polascik TJ, Mouraviev V. Focal therapy for prostate cancer. Curr Opin Urol. 2008;18:269-74.

10. Valerio M, Ahmed HU, Emberton M, Lawrentschuk N, Lazzeri M, Montironi R, Nguyen PL, Trachtenberg J, Polascik TJ. The role of focal therapy in the management of localised prostate cancer: a systematic review. Eur Urol. 2013;66:732-51.

11. Lee EW, Wong D, Prikhodko SV, Perez A, Tran C, Loh CT, Kee ST. Electron microscopic demonstration and evaluation of irreversible electroporationinduced nanopores on hepatocyte membranes. J Vasc Interv Radiol. 2012;23:107-13.

12. Bertacchini C, Margotti PM, Bergamini E, Lodi A, Ronchetti M, Cadossi R. Design of an irreversible electroporation system for clinical use. Technol Cancer Res Treat. 2007;6:313-20.

13. Davalos RV, Mir LM, Rubinsky B. Tissue ablation with irreversible electroporation. Ann Biomed Eng. 2005;33:223-31.

14. van den Bos W, de Bruin DM, Jurhill RR, Savci-Heijink CD, Muller BG, Varkarakis IM, et al. The correlation between the electrode configuration and histopathology of irreversible electroporation ablations in prostate cancer patients. World J Urol. 2015.

15. Scheffer HJ, Nielsen K, De Jong MC, Van JM TAA, Vieveen JM, Bouwman A, Meijer S, Van Kuijk C, Van Den Tol P, Meijerink MR. Irreversible electroporation for nonthermal tumor ablation in the clinical setting: a systematic review of safety and efficacy. J Vasc Interv Radiol. 2014;25:997-1011. 
16. Tsivian M, Polascik TJ. Bilateral focal ablation of prostate tissue using low-energy direct current (LEDC): a preclinical canine study. BJU Int. 2013;112:526-30.

17. Li W, Fan Q, Ji Z, Qiu X, Li Z. The effects of irreversible electroporation (IRE) on nerves. PLoS One. 2011;6:e18831.

18. Onik G, Mikus P, Rubinsky B. Irreversible electroporation: implications for prostate ablation. Technol Cancer Res Treat. 2007;6:295-300.

19. Neal RE, Millar JL, Kavnoudias H, Royce P, Rosenfeldt F, Pham A, Smith R, Davalos RV, Thomson KR. In vivo characterization and numerical simulation of prostate properties for non-thermal irreversible electroporation ablation. Prostate. 2014;74:458-68.

20. Rubinsky B. Irreversible Electroporation. 2010. ISBN: 978-3-642-05419-8.

21. Valerio M, Stricker PD, Ahmed HU, Dickinson L, Ponsky L, Shnier R, Allen C, Emberton M. Initial assessment of safety and clinical feasibility of irreversible electroporation in the focal treatment of prostate cancer. Prostate Cancer Prostatic Dis. 2014;17:343-7.

22. Ting F, Tran M, Böhm M, Siriwardana A, Van Leeuwen PJ, Haynes A-M, Delprado W, Shnier R, Stricker PD. Focal irreversible electroporation for prostate cancer: functional outcomes and short-term oncological control. Prostate Cancer Prostatic Dis 2015(August):1-7.

23. van den Bos W, de Bruin DM, van Randen A, Engelbrecht MRW, Postema AW, Muller BG, et al. MRI and contrast-enhanced ultrasound imaging for evaluation of focal irreversible electroporation treatment: results from a phase I-II study in patients undergoing IRE followed by radical prostatectomy. Eur Radiol. 2015.

24. Ahmed HU. The index lesion and the origin of prostate cancer. N Engl J Med. 2009:361:1704-6.

25. Wei JT, Dunn RL, Litwin MS, Sandler HM, Sanda MG. Prostate Cancer Index Composite (Epic) for comprehensive assessment of health-related. Urology. 2000;56:899-905.

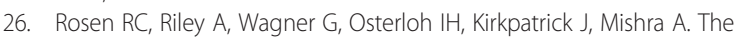
international index of erectile function (IIEF): a multidimensional scale for assessment of erectile dysfunction. Urology. 1997;49:822-30.

27. Barry MJ. Evaluation of symptoms and quality of life in men with benign prostatic hyperplasia. Urology. 2001;58(6 Suppl 1):25-32.

28. de la Rosette J, Ahmed H, Barentsz J, Johansen TB, Brausi M, Emberton M, Frauscher F, Greene D, Harisinghani M, Haustermans K, Heidenreich A, Kovacs G, Mason M, Montironi R, Mouraviev V, de Reijke T, Taneja S, Thuroff S, Tombal B, Trachtenberg J, Wijkstra H, Polascik T. Focal therapy in prostate cancer-report from a consensus panel. J Endourol. 2010:24:775-80.

29. Hu Y, Ahmed HU, Carter T, Arumainayagam N, Lecornet E, Barzell W, Freeman A, Nevoux P, Hawkes DJ, Villers A, Emberton M, Barratt DC. A biopsy simulation study to assess the accuracy of several transrectal ultrasonography (TRUS)-biopsy strategies compared with template prostate mapping biopsies in patients who have undergone radical prostatectomy. BJU Int. 2012;110:812-20.

30. Crawford ED, Rove KO, Barqawi AB, Maroni PD, Werahera PN, Baer CA, Koul HK, Rove CA, Lucia MS, La Rosa FG. Clinical-pathologic correlation between transperineal mapping biopsies of the prostate and threedimensional reconstruction of prostatectomy specimens. Prostate. 2013;73:778-87.

31. Kuru TH, Roethke MC, Rieker P, Roth W, Fenchel M, Hohenfellner M, Schlemmer HP, Hadaschik BA. Histology core-specific evaluation of the European Society of Urogenital Radiology (ESUR) standardised scoring system of multiparametric magnetic resonance imaging (mpMRI) of the prostate. BJU Int. 2013;112:1080-7.

32. Smeenge M, Mischi M, Laguna Pes MP, de la Rosette JJMCH, Wijkstra H. Novel contrast-enhanced ultrasound imaging in prostate cancer. World J Urol. 2011:29:581-7.

33. Ahmed HU, Hindley RG, Dickinson L, Freeman A, Kirkham AP, Sahu M, Scott R, Allen C, Van der Meulen J, Emberton M. Focal therapy for localised unifocal and multifocal prostate cancer: a prospective development study. Lancet Oncol. 2012;13:622-32.

34. Ahmed HU, Zacharakis E, Dudderidge T, Armitage JN, Scott R, Calleary J, Illing R, Kirkham A, Freeman A, Ogden C, Allen C, Emberton M. Highintensity-focused ultrasound in the treatment of primary prostate cancer: the first UK series. Br J Cancer. 2009;101:19-26.

35. Ahmed HU, Freeman A, Kirkham A, Sahu M, Scott R, Allen C, Van Der Meulen J, Emberton M. Focal therapy for localized prostate cancer: a phase I/II trial. J Urol. 2011;185:1246-54.
36. Epstein Jl, Walsh PC, Carmichael M, Brendler CB. Pathologic and clinical findings to predict tumor extent of nonpalpable (stage T1c) prostate cancer JAMA. 1994;271:368-74.

37. Muller BG, Fütterer JJ, Gupta RT, Katz A, Kirkham A, Kurhanewicz J, Moul JW, Pinto PA, Rastinehad AR, Robertson C, de la Rosette J, Sanchez-Salas R, Jones JS, Ukimura O, Verma S, Wijkstra H, Marberger $\mathrm{M}$. The role of magnetic resonance imaging (MRI) in focal therapy for prostate cancer: recommendations from a consensus panel. BJU Int. 2014:113:218-27.

38. Villers A, Puech P, Mouton D, Leroy X, Ballereau C, Lemaitre L. Dynamic contrast enhanced, pelvic phased array magnetic resonance imaging of localized prostate cancer for predicting tumor volume: correlation with radical prostatectomy findings. J Urol. 2006;176:2432-7.

39. Tran M, Thompson J, Böhm M, Pulbrook M, Moses D, Shnier R, Brenner P, Delprado W, Haynes AM, Savdie R, Stricker PD. Combination of multiparametric MRI and transperineal template-guided mapping biopsy of the prostate to identify candidates for hemi-ablative focal therapy. BJU Int. 2016;117:48-54

40. van Gemert MJC, Wagstaff PGK, de Bruin DM, van Leeuwen TG, van der Wal AC, Heger M, van der Geld CWM. Irreversible electroporation: just another form of thermal therapy? Prostate. 2015;75:332-5.

\section{Submit your next manuscript to BioMed Central and we will help you at every step:}

- We accept pre-submission inquiries

- Our selector tool helps you to find the most relevant journal

- We provide round the clock customer support

- Convenient online submission

- Thorough peer review

- Inclusion in PubMed and all major indexing services

- Maximum visibility for your research

Submit your manuscript at www.biomedcentral.com/submit 